\title{
Challenges of postgraduate critical care nursing program in Iran
}

\author{
Nahid Dehghan Nayeri ${ }^{1}$, Esmaeil Shariat*2 ${ }^{*}$ Zahra Tayebi ${ }^{3}$, Majid Ghorbanzadeh ${ }^{4}$
}

\begin{abstract}
Background: The main philosophy of postgraduate preparation for working in critical care units is to ensure the safety and quality of patients' care. Increasing the complexity of technology, decision-making challenges and the high demand for advanced communication skills necessitate the need to educate learners. Within this aim, a master's degree in critical care nursing has been established in Iran. Current study was designed to collect critical care nursing students' experiences as well as their feedback to the field critical care nursing.

Methods: This study used qualitative content analysis through in-depth semi-structured interviews. Graneheim and Lundman method was used for data analysis.

Results: The results of the total 15 interviews were classified in the following domains: The vision of hope and illusion; shades of grey attitude; inefficient program and planning; inadequacy to run the program; and multiple outcomes: Far from the effectiveness. Overall findings indicated the necessity to review the curriculum and the way the program is implemented.

Conclusion: The findings of this study provided valuable information to improve the critical care-nursing program. It also facilitated the next review of the program by the authorities.
\end{abstract}

Keywords: Nursing curriculum, Critical care nursing, Nursing student

Copyright $₫$ Iran University of Medical Sciences

Cite this article as: Dehghan Nayeri N, Shariat E, Tayebi Z, Ghorbanzadeh M. Challenges of postgraduate critical care nursing program in Iran. Med J Islam Repub Iran. 2017 (13 Feb);31:10. https://doi.org/10.18869/mjiri.31.10

\section{Introduction}

Introducing and extending modern critical care units over the past thirty years with the increasing complexity of patient care conditions require qualified nurses, who have acquired not only excellent knowledge and professional skills to assess patients and ability to make quick decisions in emergency situations, but also have excellent communication with patients and are equipped with leadership skills $(1,2)$. Modern critical care nurses need to become familiar with ever growing high technology and be competent in providing excellent care to patients (3).

The main aim of preparing the nurses in critical care program is to ensure patient safety and high quality care.

Corresponding author: Esmaeil Shariat, arshiashariat@yahoo.com

1. Nursing and Midwifery Care Research Center, School of Nursing and Midwifery, Tehran University of Medical Sciences, Tehran, Iran

2. School of Nursing and Midwifery, Tehran University of Medical Sciences, Tehran, Iran.

3. School of Nursing and Midwifery, Alborz University of Medical Sciences, Karaj, Iran.

4. School of Nursing, Baqiyatallah University of Medical Sciences, Tehran, Iran.
Being innovative and confident to make decisions are the key elements of effective nursing in critical care (4). Furthermore, increasing patients' expectations and awareness of the need to critical care nurses calls for skillful nurses more than ever (3). This will be achieved only if learners are properly prepared for the future role.

Therefore, postgraduate curriculum must be more clinical and focused on practical skills (4). However, some studies claim that current curriculums in critical care fails to prepare students for these situations, which could cause serious frustration and disappointment in future nursing $\operatorname{staff}(5)$.

Developing well-structured curriculum to improve

$\uparrow$ What is "already known" in this topic:

Critical care nurses need to be competent in providing excellent care to patients. In Iran, current curriculums in critical care fail to prepare the nursing students properly to manage critical situations.

$\rightarrow$ What this article adds:

For the problems in current critical care nursing in Iran five categories were identified. Analyzing students' experiences and feedbacks revealed ineffectiveness and incompetency in critical care nursing students. 
nursing education is indeed vital to effectively train competent nurses. The curriculum is seen as the blueprint for professional growth (6). There are several challenges to develop a curriculum for critical care nursing in Iran, including the absence of an appropriate model of education that could be adopted rapidly in accordance with the clinical environments and that could accommodate the unique needs of diverse cultural needs of ever-growing technology and patients' expectations.

Many of established critical care nursing programs in the world offer a brief experience of critical care to learners. Therefore, the main challenge is to design and implement a comprehensive, high quality and costeffective curriculum, which aims to provide sufficient training in the clinical setting (7).

To educate competent nurses, the curriculum for critical care nursing in master's degree was approved in Iran in 2008. To improve the quality of this program, it is crucial to assess the content and the outcome of the program. One of the most reliable means in the evaluation of a program is through analysis of students' experience and feedback. Students' feedbacks have a positive effect on the module itself, the program in general, and possibly the future assessment and formation of additional modules (if required).

\section{Methods}

Given that a deep understanding of challenges of this program is less likely to be possible through quantitative methods, this research adopted a qualitative content analysis approach to reach a comprehensive understanding of critical care nursing curriculum in Iran.

Students in different stages of training, both male and female, from three different faculties in Tehran and two other cities participated in this study as a maximum variant sample. Confidentiality was adhered in all the interviews. Students were given as much as necessary information on the objectives of the study. We interviewed 15 students; each interview took 30 to 65 minutes.

Through the individual semi-structured interview, students were asked open questions: "How was your experience since you started this program? What are the strengths and weaknesses of the program? What was your expectation from this program and have they been met?" Further clearing questions were asked based on students' responses, including: Can you explain it more, or what do you mean about this? Data collection and analysis continued until categories were saturated and there was no new information.

The conventional content analysis was used because this approach allows the findings to be derived from the participants' experiences (8-10). In addition, the researchers avoid using predefined categories and instead allow the categories and their names to be derived from the data (11).

We adapted Graneheim \& Lundman method for data analysis. Through an in-depth review of interviews, a broad and general comprehension of the content was achieved. The unit of analysis, which could have been a word, phrase, a sentence or a paragraph, was the students experiences of going through the Master's degree in critical care nursing. Having read our interviews' transcript meticulously, we started the coding process. We used in vivo coding technique, and the codes were compared with each other and categorized into strata based on their similarities and differences. The codes and categories were revised gradually until all codes were placed in suitable categories.

\section{Ethical Considerations}

This paper was a result of a research project approved by the Ethics Committee of Tehran University of Medical Sciences. Informed consent to participate in the study was obtained from the students. Interviews, data collection and storage occurred fully in compliance with data protection. Students were assured that data were collected only for research purposes and they could leave the study at any stage if they did not wish to continue.

\section{Results}

We categorized the results into 5 themes which are shown in Table 1.

\section{I- The Vision of Hope and Illusion}

The first domain pointed to the group of students who chose the field passionately; however, after a while they felt frustrated as not only their learning needs were not met but also they saw the prospect of their career as dark and gloomy.

\section{a. Entry with Motivation}

Most of the students emphasized that the clinical aspect and having specialized skills made them to choose this sub specialty.

"I chose this specialty because of its specialized view to nursing."

"I thought I should take this specialized field to improve my critical thinking."

b. Ambiguity of Clinical Status; Future Clinical Role

Under this category, students mentioned their concerns about the uncertain future and unclear career prospect. They discussed a number of issues. For example, they believed that there was no practical difference between this specialized Master's degree and the Bachelor's degree in nursing, and regretted to have chosen this field, and they saw no opportunity to continue to the $\mathrm{PhD}$ degree in this specialization.

"I don't know what my career would be like in the future; I don't know my role in the clinical setting. I regret choosing this specialty; however, I have to finish my studies so I could my degree. . Our role is not recognized in hospitals."

"We wish there was a PhD degree for this major and it had more practical modules."

\section{II-Shades of Grey Attitude}

The Second domain emphasized the medical aspect rather than a holistic and humanistic view to the profession and lack of caring. 
Table 1. Analysis of students' experiences regarding critical care nursing program

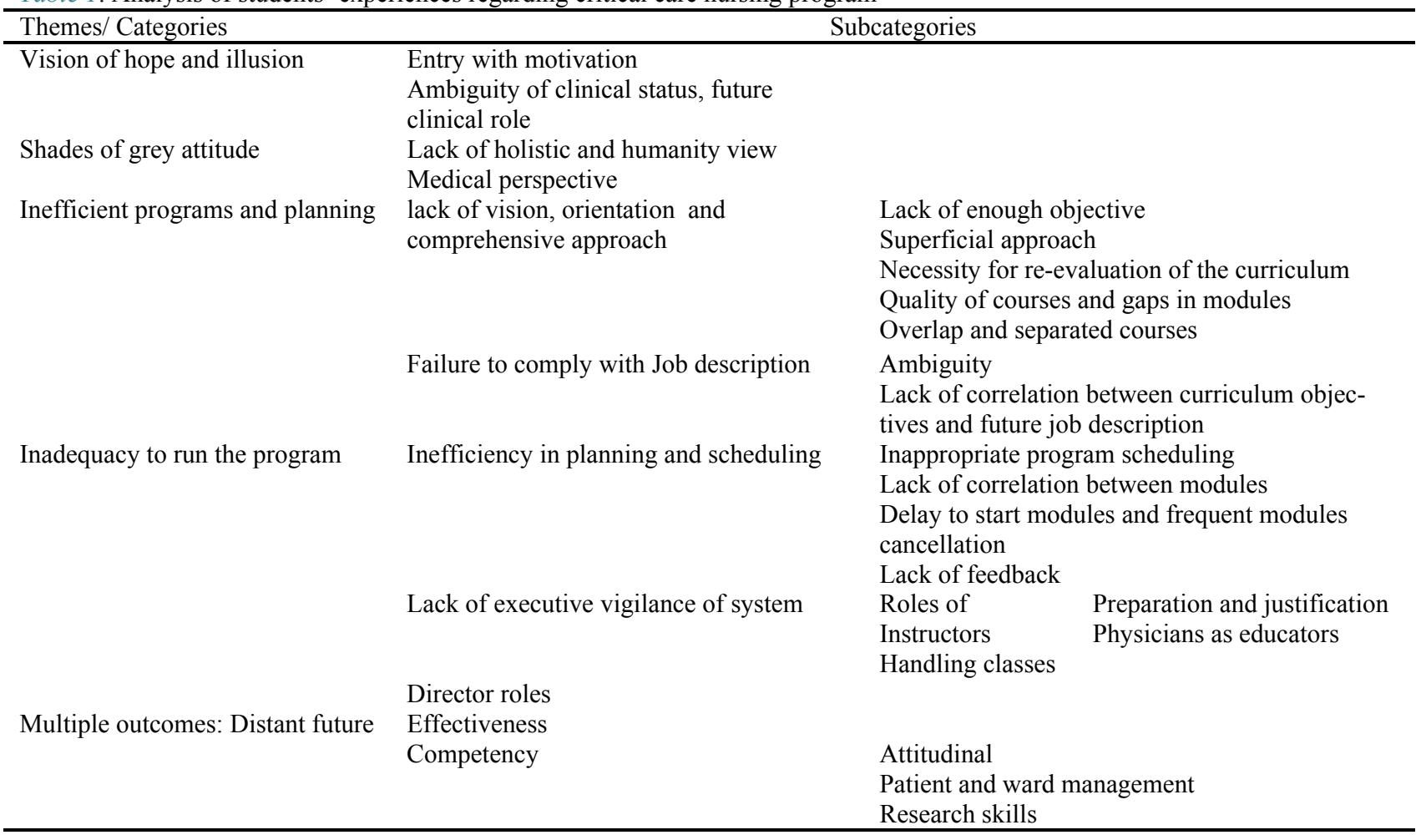

"I feel their first aim is to train physicians and not a critical care nurse."

"We were expecting a holistic view to the patients, but this was not the case."

"We do not receive any training in regards to patients' families, patients' environments, etc."

\section{III- Inefficient Planning}

Issues under inefficient planning include lack of vision, orientation and comprehensive approach and failure of curriculum design and objectives in complying with job description.

a. Lack of Vision, Orientation and Comprehensive

The participants criticized the program as it provided the students with too many broad general modules without some meaningful objectives. In addition, they believed that the courses lack sufficient emphasis on the clinical aspect. Students mention the lack of educational policy and protocols which results in inadequate operation of the program. Participants also associated other factors to inefficient planning of the program, including structural problem in the subject design and lack of a feedback system for program designers to improve the program quality. They also requested review and evaluation of the curriculum.

"The entire Critical Care curriculum was faulty. As a result, the faculty has no choice but to employ a flawed curriculum. We have already raised our concerns. "

"Curriculum design is very shallow and lacks profound skills and knowledge."

"Since it is a new specialty and newly established, there is no protocol available for it."

Students also pointed to the necessity of putting more emphasis on specialty competency to enrich the training program. In addition, students asked for a more competent and experienced training program director.

"After two years in this specialty, I realized that this is a very vast curriculum and it is impossible to cover all modules in 18-24 months."

Students frequently discussed curriculum re-evaluation and requested to employ necessary measures for curriculum quality assurance. They enlightened that curriculum assessment be carried out by the nurses. The physicians designed the original curriculum. They also urged their feedback to be discussed with the review panel. Furthermore, they pointed to the importance of bench marking with other pioneer countries.

"I think we should do a re-review of curriculum, this time nurses should lead the review, and the panel should be selected from the faculty that offer this curriculum."

"It is better to see other leading countries. It helps to achieve a better vision to design a more efficient curriculum."

b. Failure to Comply with Job Description

This include uncertainty in nurses' role in relation to their responsibility and also lack of correlation between critical care nurses' job description and the curriculum and the poor quality of curriculum content. Students believed that vague and imprecise description of their future role had a major effect in inadequacy of the training program. Students pointed to the need to develop a clear job description with the emphasis on the necessity of developing the curriculum based on job description.

One of the trainees' statement is as follows:

"One of the weaknesses of the program is that we are not clear about our future role. They must first describe 
the job plan and then train us."

Students also mentioned lack of flexibility in the curriculum. They requested clinical leadership training. It brought to our attention that some subjects needs to be reviewed and updated. They raised concerns on lack of enough emphasis on patients and nurses' relationship. Moreover, trainees complained about lack of enough attention to clinical research and postgraduate education in the work place.

Students complained that due to the broad scope of subjects to be covered, none of them is discussed in detail, and the entire curriculum has a shallow view to subjects. In the meantime, some necessary practical modules were not present in the training program.

"We wanted to have a vision either through research or clinical experience, but at the end we had just bit and pieces; I had to request my employer for an additional research course."

"What we were taught in the classroom was not applicable in the clinical setting."

"Approach to the modules' content was very superficial."

"The program designer did not consider the students' requirements."

\section{Inadequacy in Running the Program}

The fourth category points to the lack of fundamental structure to run the program.

\section{a. Inefficiency in Planning and Scheduling}

This category includes ineffective implementation of the program and lack of enough preparation in terms of organizing classes and workshops. Inaccurate scheduling and disorganized teaching sessions were other issues raised by students. They also pointed to chaotic timetable, delay and cancelling the lessons and workshops and consequently wasting of study time.

Students request more organization on the offered modules in each term. They also stipulated on the reevaluation of thought modules at the end of the academic term.

"They must organize and prioritize the modules. We often had the main module first and its pre-requisite module in the next term; there was no correlation in terms of the taught subjects."

b. Lack of Executive Vigilance of System

Students also pointed to the gaps in the training system, which they believed were the results of lack of sufficient training to the instructors and employing inexperienced mentors. They reported that some instructors were not only blind to the program objectives, but also they were not aware of trainees' needs and expectations. Some trainers did not give priority to educational activities and were not aware of modern educational methods. They did not have the proper expertise. Trainees need more experienced instructors that are familiar with the educational program, are equipped with relevant qualifications, and have been trained specifically to be an instructor.

"To be honest, I want to drop out of the program. Instructors are not knowledgeable enough; they are either new graduates and not experienced or not trained in critical care."

"It would be ideal to employ trainers who are trained in critical care; hence, they know how we are going to benefit from this course. Then they could guide and support us on both clinical and research modules."

"Some of the instructors could not answer our questions, even the simple ones."

Another subcategory explains how students give feedback on physicians trainers. There were mix feelings; some believe the physicians' instructors have a positive role, specifically in terms of clinical approach, whereas others believe they do not put enough effort in training, and that they have a physician approach and not necessarily a nursing approach. When the relationship with the patients is concerned, the physician instructors are considered inadequate.

In summary, all the participants believed there should be a moderation in employing physicians in educational programs.

"Sometimes, physicians are better as trainers, as they are more skilled and practical, specifically if they are fellowship candidates, they get involved in clinical care."

"It is beneficial to use physicians; however, first they should be trained in terms of program's objectives and the nursing approach."

\section{c. Handling Classes}

The next sub-category points to the lack of enough training and skills for instructors. Students were concerned that trainers were not familiar or expert in modern teaching methods. Classes are often not interactive, they rely too much on the slides, and are sometimes too chaotic and disorganized to give the trainees some autonomy. Students were given too many time-consuming tasks without realistic benefits. Some of the subjects were often repeated frequently in different modules.

"Only respiratory session was delivered on a case presentation based approach, and the rest of the modules were delivered in a lecture based approach."

"We were asked to do too many tasks and projects, which we found useless later."

\section{d. Director Roles}

Students also pointed to the inefficiency of the training program directors. They failed to recruit expert trainers and lacked appropriate protocols to employ suitable trainers to run the program. There were several evidences indicating that trainers were not trained sufficiently and were not familiar with curriculum and the objectives of the training program.

"Directors should help develop the vision of the critical care trainers. They should have knowledge and understanding of critical care curriculum and training program. They should know our needs and what we expect of them."

"Some instructors were not experts and were only aware of basic subjects. We were surprised why we were in their placement." 


\section{Multiple Outcomes: Distant Future}

The last domain explains how far it is to achieve a fully effective training program. This is discussed exploring three categories of efficiency, competencies, and training.

\section{a. Effectiveness}

In terms of effectiveness, it was reported that the program was not effective as a result of being a new concept and not well-structured. Students mentioned that they did not have enough confidence and the prospect of their potential career did not seem satisfying. The trainees felt undervalued. They felt disappointed by not achieving their academic goals. They were concerned of wasting the time and money on pursuing this field. Candidates explained that they failed to achieve some of their goals, such as being efficient and innovative.

"This training improved our skills only by $20 \%$; this is far less than what we expected."

"In terms of skills and knowledge, we did not develop much."

"We expected to receive training in critical care, and have more responsibility; however, this never happened."

An educational course can be called "effective" as long as students learn new skills and knowledge. However, candidates expressed different experiences in this category. They said they were expecting structural learning, but they left disappointed.

The trainees assert that the critical care program failed to increase their knowledge and skills. They were involved in learning the subjects without clear objectives. There were too much stress and effort on learning to work with modern educational technologies, such as Word and PowerPoint. Trainees often lacked the relevant skills and knowledge, because they lost the opportunity to practice. They were not satisfied but afraid to express their views. In the meanwhile, some pointed that they learn how to keep themselves up to date and learn how to continue professional educational activities independently.

"We successfully passed all modules, but in practice we struggle in challenging situations. We are not sure how to plan."

"This program was so useless; those who were in runthrough program cannot even diagnose PVC (preventricular capture)."

"The highlight of the course for me was how to keep myself up to date."

\section{b. Competency}

To achieve competency is one of the expected outcomes of the training course. Candidates confess that their attitude toward clinical approach, training, and research has been improved. Their vision expanded, they developed a more holistic approach to patients and clinical challenges. Students gained academic views that enabled them to understand subjects in national and international conferences. Students often could perform critical analysis. However, some participants expressed that the course failed to improve their critical thinking skills.

"My attitude toward my role and job has changed dramatically in a positive way; I think this is a result of critical care training program."

"I often empathize with my patients; I understand them better now."

The second aspect of competency in critical care trainees is being able to manage clinical setting independently. Candidates were expected to be taught how to manage clinical setting and patients independently. Participants expected to be given more responsibility in hospitals and to be able to work independently. In addition, they prefer to receive further training to build a healthy relationship with patients and their families. However, trainees reported the following shortcomings on this matter: Failing to meet their initial expectations, failing to give trainees enough accountability toward patients, failing to provide opportunity for trainees to experience clinical challenges. Hence, trainees are not fully prepared to encounter clinical scenarios.

"What I'm going to expect myself once I have been graduated? I expect to manage a patient and support him independently; I do not this this would happen."

\section{Discussion}

The outcome of this study defines five main domains. This study highlighted challenges in critical care nursing program that requires further attention. There is some evidence indicating that similar training programs in other parts of the world were challenged with the same problems, such as students' competency, quality of courses, and curriculum content (12).

The first theme points to the group of students who chose this program to specialize, but they appeared to be disappointed because they faced similar challenges postdegree as earlier.

One study explored the reasons of why people choose nursing. One of the reported outcomes was the high demand for graduates (13). This supports our finding.

A study reported that according to nursing students, the strongest factor to choose nursing as a career is to help and provide care for people (14). There are many reasons that motivate people to take further postgraduate training. This mainly depends on the nature of the job and the jobs' prospect. For instance, one study showed that midwifes tend to take further postgraduate training to work unsupervised in private practice (15).

Some studies have found that although nursing training evolved massively over the last few years, it still has several challenges on its way (16). Essentially, the design of educational programs should be based on the desires, needs, conditions and opportunities of the community $(17,18)$; otherwise, this could result in the trainees' disappointment and disengagement.

The second theme, which obscures the training programs, is 'Shades of grey attitude'. Lack of sufficient attention on nursing aspects and too much emphasis on medical vision were two of the concerns. In addition, lack of holistic view on nursing and inadequate patient approach were other issues raised by the trainees. It should be taken into account that for some candidates the program was new and still developing. Another researcher found similar results supporting lack of holistic approach to nursing program. Most of these programmes put too much emphasis on understanding disease rather than how 
to deliver right care to patients (18-20). Holistic approach to patient care has been proposed to prepare nurses for real work environments. This method is more effective in terms of problem- solving, reasoning and mutual learning $(21,22)$.

Stressing on medical aspect of nursing program has been criticized in many occasions in the past. For instance, Yazdannik and his colleague believe that this could result in training a physician assistant rather than a nurse $(23,24)$. Another study reveals that ambiguity in nurses' role may result in non-functioning professional relationship between doctors and nurses (25).

Given that in our study critical care nursing program was designed by physicians, it was expected to undermine caring and nursing features.

Third category intended to discuss inefficient programs. Students criticized the course with regards to its vague objectives. They also challenged superficial approach and lack of correlation between curriculum objectives and the clinical aspect of future job description. Researchers argue that an educational program should be comprehensive and cover all aspects of curriculum, including providing enough opportunities to develop skills (26).

Another issue discussed in this category was the necessity of putting more emphasis in terms of a specialty course, and delegation of management to highly expert individuals. Interestingly, other researchers also concluded that job description is unclear, and hence the training is vague for this group of specialist nurses (27). Another study indicated that lack of expertise $(79 \%)$ caused poor quality of training sessions (28).

Another important concern that has been discussed was the lack of comprehensive approach. Poor quality of training sessions and gaps in module contents plus ambiguity of program in terms of future required skills for nurses were classified under this group. A review study referred to highlighted uncertainty in students' responsibility in the ward as a major educational challenge (30). Also, other reports support this ambiguity in trainees' responsibility (27) and some repetition in modules between MSN and PhD programs (30).

The next category indicates inadequacy to run the program and gaps in the modules. We discussed this under three main categories: Inefficiency in planning and scheduling, lack of executive vigilance of system and the role of training program director. Some studies found that most of training course content, sequence and scope of the subjects failed to prepare individuals for workplace challenges (30).

In this category, we analyzed the important role of instructors and their teaching skills. Other studies support our findings in relation to the constructive role of expert instructors to improve shortcomings. In one review study, lack of clinical skills, lack of experience in clinical training and fear of clinical training in general were listed as the challenges. Therefore, it is suggested that all instructors be supported and trained in clinical skills training (31).

Finally yet importantly, we discussed issues under multiple outcomes and unachievable prospect. Three sub- categories emerged within our discussion: Poor effectiveness, competency, and learning. There are several studies supporting the fact that the majority of Iranian Nursing schools fail to meet their planned objectives (23) and there is evidence of incompetency in the trained nurses (32).

Under the same line of analysis, a study of Isfahan University found that medical learners' skills in terms of their attitudes, critical analysis and reasoning all have been scored below the required standard even after entry to clinical practice (33). Some studies outside Iran also reported a similar challenge; i.e., improving critical analysis skill in the trainees (34).

\section{Conclusion}

This study aimed to assess the challenges of the critical care nursing program. We found challenges in the design and implementation of the program. Moreover, the outcome revealed ineffectiveness and incompetency in critical care nursing trainees.

\section{Acknowledgements}

This study was approved by The Ethics Committee of Tehran University of Medical Sciences. We thank all of the participants.

\section{Conflict of Interest: None declared.}

\section{References}

1. Grossman SC, Valiga TM. The new leadership challenge: Creating the future of nursing: FA Davis 2012.

2. Burns P, Poster EC. Competency development in new registered nurse graduates: closing the gap between education and practice. Journal of Continuing Education in Nursing 2008;39(2):67-73.

3. McGrath M. The challenges of caring in a technological environment: critical care nurses' experiences. Journal of clinical nursing 2008;17(8):1096-104.

4. Rattray JE, Paul F, Tully V. Partnership working between a Higher Education Institution and NHS TRUSTS: developing an acute and critical care module. Nursing in critical care 2006;11(3):111-7.

5. Ratanawongsa N, Teherani A, Hauer KE. Third-year medical students' experiences with dying patients during the internal medicine clerkship: a qualitative study of the informal curriculum. Academic Medicine 2005;80(7):641-7.

6. Lange B, Purnell MJ. Curriculum as Environment: A Focus Group Study. Holistic nursing practice 2011;25(4):184-91.

7. Jeffries PR. Development and testing of a hyperlearning model for design of an online critical care course. Journal of Nursing Education. 2005;44(8):366-72.

8. Hsieh HF, Shannon SE. Three approaches to qualitative content analysis. Qualitative health research 2005;15(9):127788 .

9. Elo S, Kyngäs H. The qualitative content analysis process. Journal of advanced nursing 2008;62(1):107-15.

10. Cloyes KG, Berry PH, Reblin M, Clayton M, Ellington L. Exploring Communication Patterns Among Hospice Nurses and Family Caregivers: A Content Analysis of In-home Speech Interactions. Journal of Hospice \& Palliative Nursing 2012; 14(6):426-37.

11. Krippendorff K, Bock MA. The content analysis reader: Sage 2009. 
12. Salminen L, Stolt M, Saarikoski M, Suikkala A, Vaartio H, Leino-Kilpi H. Future challenges for nursing education-A European perspective. Nurse Education Today 2010;30(3):2338.

13. Tayebi Z, Dehghan-Nayeri N, Negarandeh R, Shahbazi S. Motives for entering nursing in Iran: A qualitative study. Iranian journal of nursing and midwifery research 2013;18(1):59.

14. Abaszadeh A, Borhani F. Factors affecting discipline (Major) choice among newly admitted students of nursing in Kerman university of medical sciences. Iranian Journal of Medical Education 2012;11(6):600-8.

15. Kamali S, Jafari E, Fathi A. Correlation Between Academic Achievement and Self-Esteem in Students of Zanjan Faculty of Nursing and Midwifery 2009. Journal of Medical Education Development 2009;2(2):17-24.

16. Farsi Z, Dehghan-Nayeri N, Negarandeh R, Broomand S. Nursing profession in Iran: an overview of opportunities and challenges. Japan Journal of Nursing Science 2010;7(1):9-18.

17. McCullagh MC, Berry P. A Safe and Healthful Work Environment Development and Testing of an Undergraduate Occupational Health Nursing Curriculum. Workplace health \& safety 2015: 2165079915584127.

18. Ndawo MG. Challenges experienced by nurse educators on the delivery of content laden curriculum at a nursing college in Gauteng. Journal of Nursing Education and Practice 2015;5(11):p103.

19. Komenda M, Schwarz D, Švancara J, Vaitsis C, Zary N, Dušek L. Practical use of medical terminology in curriculum mapping. Computers in Biology and Medicine 2015;63:74-82.

20. Sitlington $H$, Coetzer A. Using the Delphi technique to support curriculum development. Education + Training 2015;57(3):306-21.

21. Iwasiw CL, Goldenberg D, Andrusyszyn M-A. Curriculum development in nursing education: Jones \& Bartlett Publishers; 2014.

22. Keating SB. Curriculum development and evaluation in nursing: Springer Publishing Company 2014.

23. Yazdannik Ar, Yousefy A, Mohammadi S, Arazi Gt. A Glimpse in the challenges in Iranian academic Ms Nursing Education 2014.

24. Yousefy A, reza Yazdannik A, Mohammadi S. Exploring the environment of clinical baccalaureate nursing students' education in Iran; A qualitative descriptive study. Nurse Education Today 2015.

25. Matziou V, Vlahioti E, Perdikaris P, Matziou T, Megapanou E, Petsios K. Physician and nursing perceptions concerning interprofessional communication and collaboration. Journal of interprofessional care 2014;28(6):526-33.

26. Merritt BK, Blake AI, McIntyre AH, Packer TL. Curriculum evaluation: Linking curriculum objectives to essential competencies. Canadian Journal of Occupational Therapy 2012;79(3):175-80.

27. Peyman H, Darash M, Sadeghifar J, Yaghoubi M, Yamani $\mathrm{N}$, Alizadeh $\mathrm{M}$. Evaluating the viewpoints of nursing and midwifery students about their clinical educational status. Iranian Journal of Medical Education 2011;10(5):1121-30.

28. Mirzabeigi G, Sanjari M, Shirazi F, Heidari S, Salemi S. Nursing students'and educators'views about nursing education in Iran 2011.

29. Jokar F, Haghani F. Nursing clinical education, the challenges facing: A Review Article. Iranian Journal of Medical Education 2011; 10(5):1153-60.

30. Farahani M, Ahmadi F. Doctoral Nursing Students' Viewpoints about the Nursing PhD Curriculum. Iranian Journal of Medical Education 2006;6(1):83-92.

31. Hickey MT. Baccalaureate nursing graduates' perceptions of their clinical instructional experiences and preparation for practice. Journal of Professional Nursing 2010;26(1):35-41.

32. Rahimaghaee F, Nayeri D, Mohammadi E. Iranian nurses perceptions of their professional growth and development. OJIN: The Online Journal of Issues in Nursing 2011;16(1):10.

33. Tashi S, Mortazavi F, Yazdani S, Mottaghipour Y. Evaluating Critical Thinking Skills in Medical Students, Isfahan University of Medical Sciences, Iran. Journal of Strides Development Medical Education 2013;9(2):170-8.

34. Chan CK, So WK, Fong DY. Hong Kong baccalaureate nursing students' stress and their coping strategies in clinical practice. Journal of Professional Nursing 2009;25(5):307-13.

35. Anblagan D, Jones NW, Costigan C, Parker AJ, Allcock $\mathrm{K}$, Aleong R, et al. Maternal smoking during pregnancy and fetal organ growth: a magnetic resonance imaging study. PLoS One 2013 Jul 3;8(7):e67223. 